\section{International Scientific Journal Theoretical \& Applied Science}

\author{
p-ISSN: 2308-4944 (print) e-ISSN: 2409-0085 (online) \\ Year: $2016 \quad$ Issue: 3 Volume: 35 \\ Published: $30.03 .2016 \quad$ http://T-Science.org
}

SECTION 27. Transport.
Andrey Stanislavovich Reshenkin professor, candidate of technical sciences, head of department

Don State Technical University, Russia v.serge.79@mail.ru

Sergey Sergeevich Vorobyev assistant professor

candidate of technical sciences

Don State Technical University, Russia

Daniil Andreevich Zacharcov student

Don State Technical University, Russia

Ruslan Nersesovich Aslanjan student

Don State Technical University, Russia

Dmitriy Sergeevich Andros student

Don State Technical University, Russia

\title{
APPLICATION OF THE GEORADAR-LOCATION FOR THE ASSESSMENT OF PASSABILITY OF VEHICLES
}

\begin{abstract}
In the given work the alternative option to methods of static and dynamic sounding, namely a georadar control method is considered on the basis of pilot studies. As a result, there is observed satisfactory coincidence of the application of control methods that allows recommending a georadar method as control for an assessment of passability of vehicles along unprepared routes of the movement.

Key words: georadar control method, assessment of passability of vehicles.

Language: Russian

Citation: Reshenkin AS, Vorobyev SS, Zacharcov DA, Aslanjan RN, Andros DS (2016) APPLICATION OF THE GEORADAR-LOCATION FOR THE ASSESSMENT OF PASSABILITY OF VEHICLES. ISJ Theoretical \& Applied Science, 03 (35): 49-58.

Soi: http://s-o-i.org/1.1/TAS-03-35-9 Doi: crossef http://dx.doi.org/10.15863/TAS.2016.03.35.9

\section{ПРИМЕНЕНИЕ ГЕОРАДИОЛОКАЦИИ ДЛЯ ОЦЕНКИ ПРОХОДИМОСТИ ТРАНСПОРТНЫХ СРЕДСТВ}

Аннотация: В работе на основе экспериментальных исследований рассматривается альтернативный вариант методам статического и динамического зондирования, а именно георадиолокационный метод контроля. В результате наблюдается удовлетворительное совпадение применения методов контроля, что позволяет рекомендовать георадиолокационный метод в качестве контрольного для оценки проходимости транспортных средств по неподготовленным маршрутам движения.

Ключевые слова: георадиолокационный метод контроля, оценка проходимости транспортных средств.
\end{abstract}

Причиной рассмотрения вопроса оценки проходимости транспортных средств по неподготовленным грунтовым покрытиям обусловлена необходимостью решения задач связанных с доставкой различных грузов в труднодоступные места.

В настоящее время с целью разведки предполагаемых маршрутов движения используются пенетрационные методы статического и динамического зондирования [1].

В их основе лежит определение характеристик сопротивления грунта по результатам вдавливания различных зондов в грунт. При достаточной простоте применяемых методов они обладают существенным недостатком. По своей сути пенетрация дает дискретные значения характеристик грунта на предполагаемом маршруте движения 
транспортных средств, что может привести к отсутствию возможности движения на некоторых участках маршрута.

В связи с этим более предпочтительным для решения такого типа задач является применение методов непрерывной оценки состояния грунтового полотна на маршрутах движения транспортных средств. Одним из таких является георадиолокационный метод [2].

Идея метода георадиолокационного зондирования состоит в излучении импульсов электромагнитных волн и регистрации сигналов, отраженных от границ раздела слоев зондируемой среды, имеющих различные электрофизические свойства.
Наиболее важными параметрами, характеризующими возможности применения метода георадиолокации в различных средах, являются удельное затухание и скорость распространения электромагнитных волн в среде, которые определяются ее электрическими свойствами.

Целью настоящей работы является установление связи данных пенетрации различных грунтовых покрытий и георадиолокации.

Пенетрация проводилась малым наконечником в грунтовой лаборатории РГУПС (рис. 1). Диаметр наконечника - 35 мм.

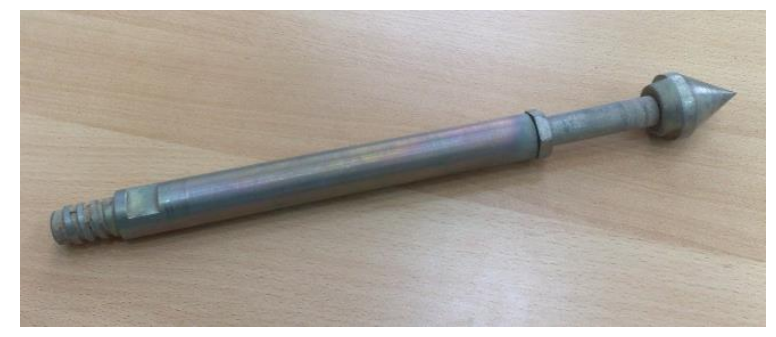

\section{Рисунок 1 - Пенетрометр с малым наконечником.}

Георадиолокация проводилась с использованием антенного блока АБ-1700, работающего на частоте 1700 МГц (рис. 2).

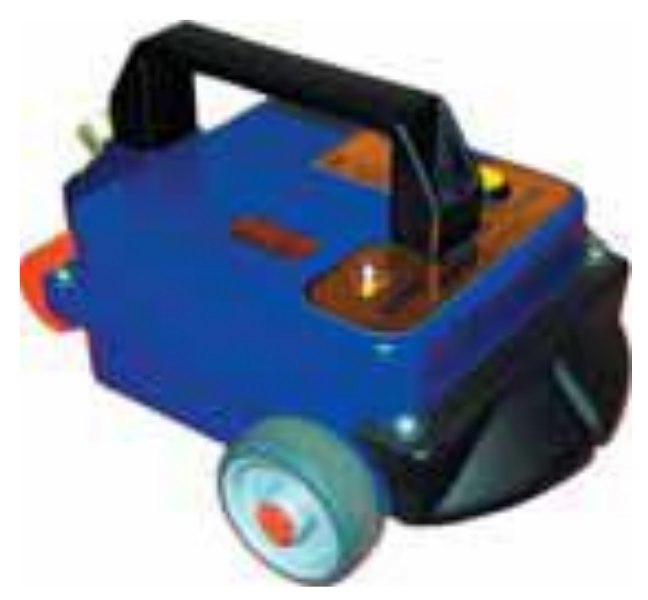

Рисунок 2 - Антенный блок АБ-1700.

Испытуемый объем с грунтом (речной песок, глина), размеры 40х40х40 см.

Измерения обоими методами проводились по следующей схеме. Задавалась массовая влажность грунта, которая рассчитывалась по формуле:

$$
M_{B}=\frac{c}{1-c} M_{\Pi}
$$

где $\mathrm{M}_{\Pi}$ и $\mathrm{M}_{\mathrm{B}}$ - массы песка и воды; $c$ - значение влажности в процентах. Параметр с варьировался и принимал значения: $0 \%, 5 \%, 7.5 \%, 10 \%, 12.5 \%$, $15 \%$.

После увлажнения полученный грунт испытывал динамическое уплотнение с силой $F=m g$ с числом ударов 10 .

По первому методу (пенетрация) для каждого значения влажности грунта с получено число ударов наконечника до его полного погружения и записано в таблицу 1 и таблицу 2 для песка и глины соответственно. Для набора 


\begin{tabular}{|c|c|c|c|c|c|c|}
\hline Impact Factor: & $\begin{array}{l}\text { ISRA (India) } \\
\text { ISI (Dubai, UAE } \\
\text { GIF (Australia) } \\
\text { JIF }\end{array}$ & $\begin{array}{l}=1.344 \\
=0.829 \\
=0.564 \\
=1.500\end{array}$ & $\begin{array}{l}\text { SIS (USA) } \\
\text { PИНЦ (Russia) } \\
\text { ESJI (KZ) } \\
\text { SJIF (Morocco) }\end{array}$ & $\begin{array}{l}=0.912 \\
=0.179 \\
=1.042 \\
=2.031\end{array}$ & $\begin{array}{l}\text { ICV (Poland) } \\
\text { PIF (India) } \\
\text { IBI (India) }\end{array}$ & $\begin{array}{l}=6.630 \\
=1.940 \\
=4.260\end{array}$ \\
\hline
\end{tabular}

статистики измерения выполнены в количестве трех серий с последующим их усреднением.

Таблица 1

Песочный грунт.

\begin{tabular}{|c|c|c|c|c|}
\hline Влажность, \% & $\begin{array}{c}\text { Число ударов } \\
\text { (опыт 1) }\end{array}$ & $\begin{array}{c}\text { Число ударов } \\
\text { (опыт 2) }\end{array}$ & $\begin{array}{c}\text { Число ударов } \\
\text { (опыт 3) }\end{array}$ & $\begin{array}{c}\text { Среднее из трех } \\
\text { опытов }\end{array}$ \\
\hline 0 & 5 & 6 & 6 & 5,67 \\
\hline 5 & 15 & 17 & 17 & 16,33 \\
\hline 7,5 & 20 & 20 & 20 & 20 \\
\hline 10 & 21 & 21 & 9 & 21,33 \\
\hline 12,5 & 10 & 9 & 5 & 5,33 \\
\hline 15 & 7 & 5 & & 5,67 \\
\hline
\end{tabular}

Таблица 2

\section{Глинистый грунт.}

\begin{tabular}{|c|c|c|c|c|}
\hline Влажность, \% & $\begin{array}{c}\text { Число ударов } \\
\text { (опыт 1) }\end{array}$ & $\begin{array}{c}\text { Число ударов (опыт } \\
\text { 2) }\end{array}$ & $\begin{array}{c}\text { Число ударов } \\
\text { (опыт 3) }\end{array}$ & $\begin{array}{c}\text { Среднее из трех } \\
\text { опытов }\end{array}$ \\
\hline 0 & 4 & 6 & 6 & 5,3 \\
\hline 5 & 18 & 20 & 22 & 20 \\
\hline 7,5 & 30 & 33 & 32 & 31,67 \\
\hline 10 & 45 & 42 & 49 & 45,33 \\
\hline 12,5 & 40 & 35 & 41 & 38,67 \\
\hline 15 & 33 & 30 & 33 & 32 \\
\hline
\end{tabular}

По второму методу (георадиолокация) получены георадарограммы для указанных значений влажности $c$ (рис. 3) и проведена их математическая обработка с определением относительной отражательной способности $\Sigma_{\text {отн }}$ грунта. Полученные данные приведены в таблице 3.

Таблица 3

Данные георадиолокации.

\begin{tabular}{|c|c|c|}
\hline Влажность, \% & Отражательная способность $\sum_{\text {отн }}$ песка & Отражательная способность $\sum_{\text {отн }} \quad$ глины \\
\hline 0 & 0,146 & 0,747 \\
\hline 5 & 0,552 & 0,85 \\
\hline 7,5 & 0,665 & 0,87 \\
\hline 10 & 0,781 & 0,885 \\
\hline 12,5 & 0,837 & 0,9 \\
\hline 15 & 0,894 & 0,91 \\
\hline
\end{tabular}




\begin{tabular}{|c|c|c|c|c|c|c|}
\hline Impact Factor: & $\begin{array}{l}\text { ISRA (India) } \\
\text { ISI (Dubai, UAE } \\
\text { GIF (Australia) } \\
\text { JIF }\end{array}$ & $\begin{array}{r}=1.344 \\
=0.829 \\
=0.564 \\
=1.500\end{array}$ & $\begin{array}{l}\text { SIS (USA) } \\
\text { PИHЦ (Russia) } \\
\text { ESJI (KZ) } \\
\text { SJIF (Morocco) }\end{array}$ & $\begin{array}{l}=0.912 \\
=0.179 \\
=1.042 \\
=2.031\end{array}$ & $\begin{array}{l}\text { ICV (Poland) } \\
\text { PIF (India) } \\
\text { IBI (India) }\end{array}$ & $\begin{array}{l}=6.630 \\
=1.940 \\
=4.260\end{array}$ \\
\hline
\end{tabular}

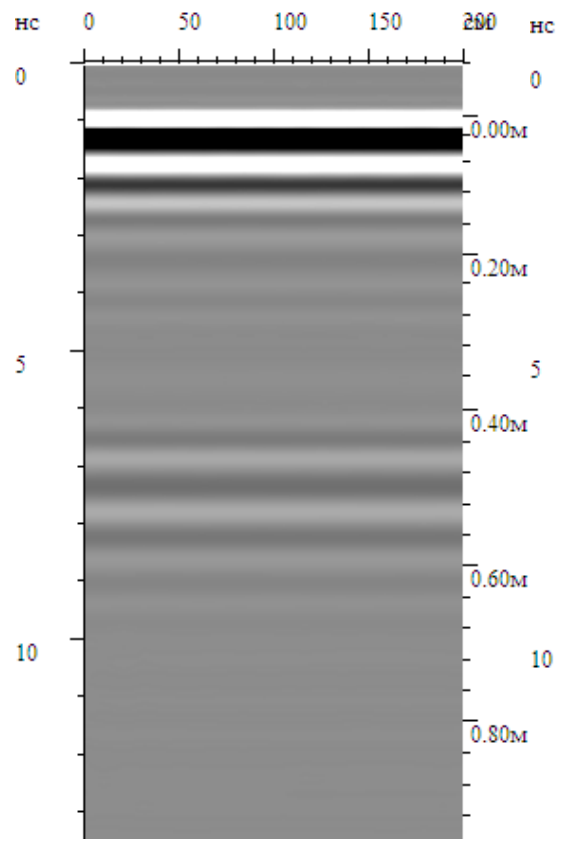

a

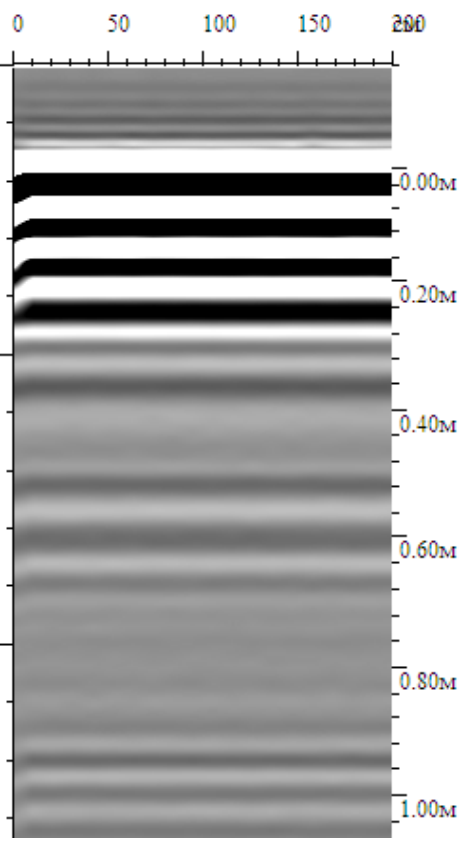

б

Рисунок 3 - Данные георадиолокации: а) песок; б) глина.

Полученные результаты эксперимента приведены в виде графиков зависимости количества ударов пенетрометра от влажности и относительной отражательной способности грунта от влажности для различных грунтов (рис. 4-7).

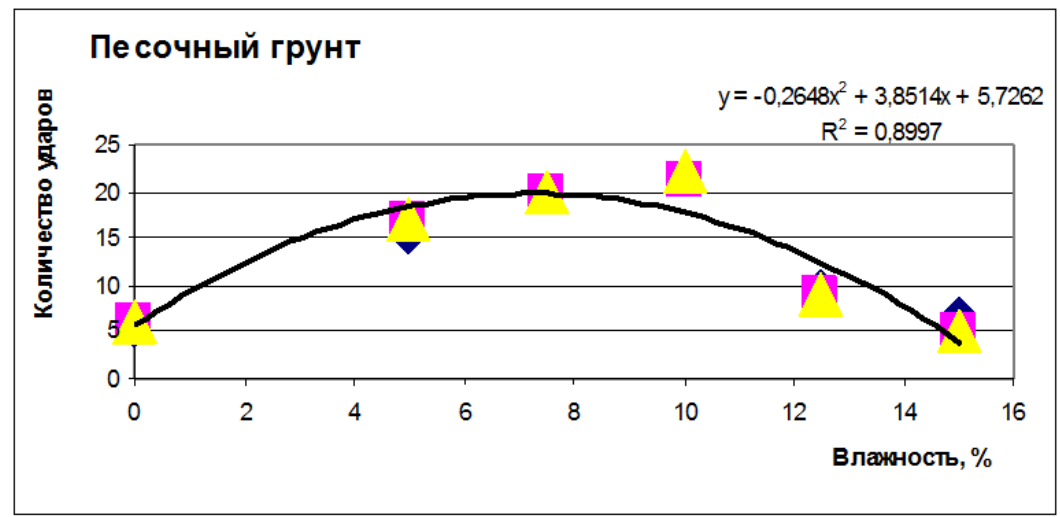

Рисунок 4 - Зависимость количества ударов пенетрометра от влажности грунта.

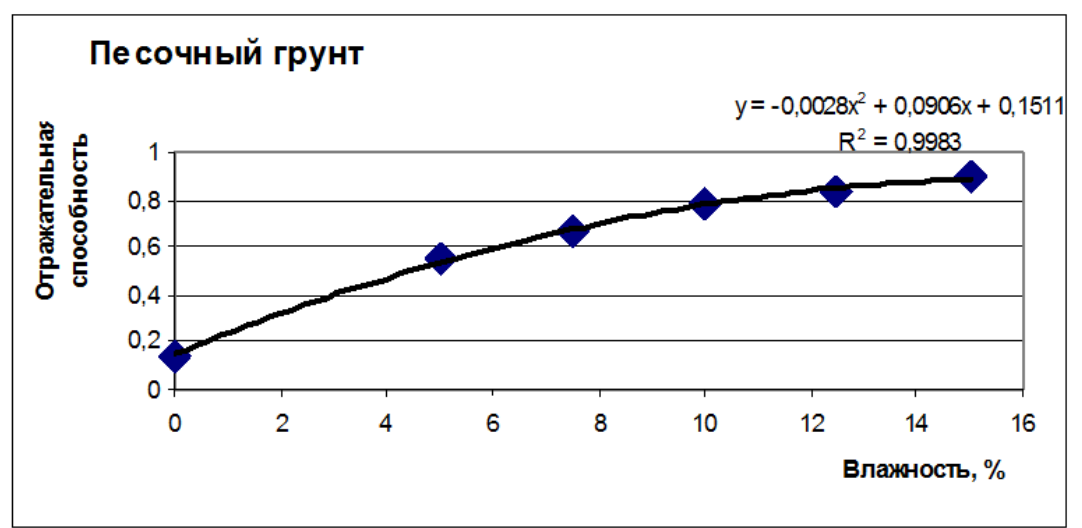

Рисунок 5 - Зависимость относительной отражательной способности грунта от влажности. 


\begin{tabular}{l|lrl|l|ll} 
& ISRA (India) & $=\mathbf{1 . 3 4 4}$ & SIS (USA) & $=\mathbf{0 . 9 1 2}$ & ICV (Poland) & $=\mathbf{6 . 6 3 0}$ \\
Impact Factor: & ISI (Dubai, UAE) $=\mathbf{0 . 8 2 9}$ & PUHЦ (Russia) & $=\mathbf{0 . 1 7 9}$ & PIF (India) & $=\mathbf{1 . 9 4 0}$ \\
& GIF (Australia) & $\mathbf{0 . 5 6 4}$ & ESJI (KZ) & $=\mathbf{1 . 0 4 2}$ & IBI (India) & $=\mathbf{4 . 2 6 0}$ \\
& JIF & $\mathbf{1 . 5 0 0}$ & SJIF (Morocco) & $\mathbf{2 . 0 3 1}$ & & \\
\hline
\end{tabular}

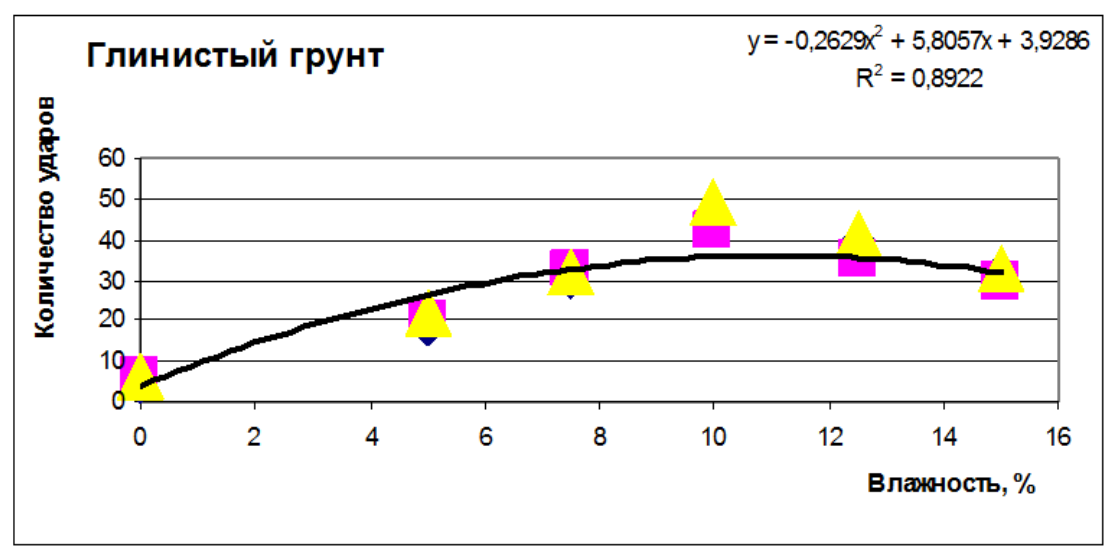

Рисунок 6 - Зависимость количества ударов пенетрометра от влажности грунта.

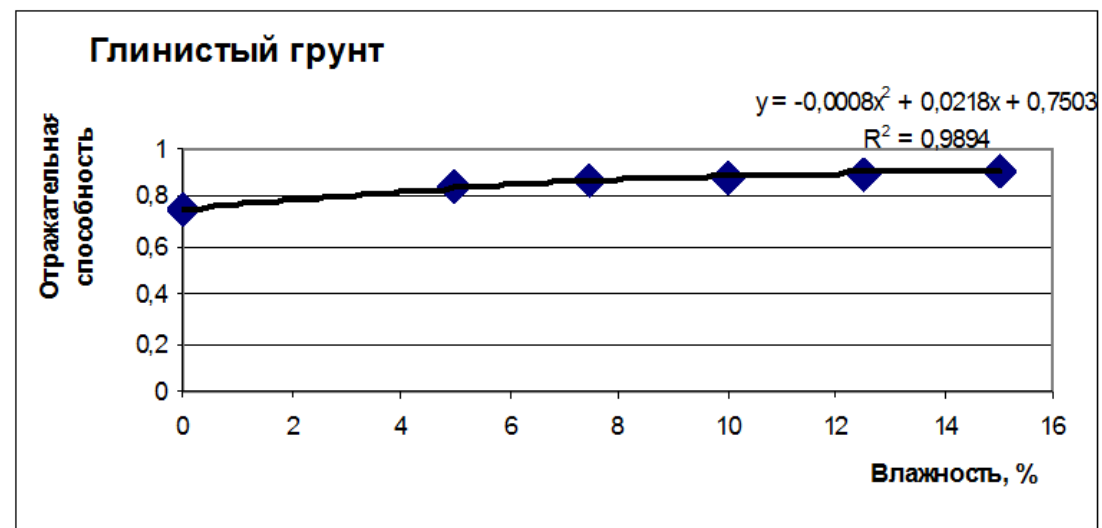

Рисунок 7 - Зависимость относительной отражательной способности грунта от влажности.

При построении зависимостей данные пенетрации обрабатывались по формуле:

$$
P_{i}=N_{i}-N_{1},
$$

где $P_{i}$ - данные, отложенные на рис. 1 и $2, N_{i}$ число ударов при влажности і \%; а отражательной способности по формуле:

$$
\widetilde{\Sigma}_{i}=k *\left(\Sigma_{i}-\Sigma_{1}\right),
$$

где $\widetilde{\Sigma}_{i}$ - данные, отложенные на рис. 1 и $2, \Sigma_{i}$ отражательные способности на влажности і \%, $k$ - коэффициент, зависящий от природы грунта.

Отражательную способность $\Sigma_{m}$ слоя грунта определяем суммированием абсолютных значений точек трассы $F n$ в слое $[0, \mathrm{rm}]$

$$
\Sigma_{m}=\sum_{i}^{m}\left|F_{i}\right|
$$

Введем относительную отражательную способность выделенного слоя соотношением:

$$
\begin{gathered}
\Sigma_{\text {отн }}=\Sigma_{m} / \Sigma_{0}, \\
\Sigma_{0}=\sum_{i}\left|F_{i}\right| \quad \text { - общая отражательная }
\end{gathered}
$$

способность.
Применяя к функции $f_{r_{m}}(x)$ преобразование Фурье, получим

$$
\Sigma_{\text {отн }}=\frac{\int_{0}^{\infty}\left|f_{r_{m}}(\omega)\right| d(\omega) \int_{0}^{r_{m}} e^{-\rho r}|\sin (\omega r)| d r}{\int_{0}^{\infty}|f(\omega)| d(\omega) \int_{0}^{\infty} e^{-\rho r}|\sin (\omega r)| d r}
$$

Тогда на частоте $\omega$ относительная отражательная способность $\Sigma_{\text {отн }}(\omega)$ определяется в виде:

$$
\Sigma_{\text {отн }}=\int_{0}^{\infty} \Sigma_{\text {отн }}(\omega) d \omega .
$$

Значение спектральной относительной отражательной способности, соответственно, имеет вид:

$$
\Sigma_{\text {отн }}(\omega)=C_{r_{m}}(\omega) \frac{\int_{0}^{r_{m}} e^{-\rho r}|\sin (\omega r)| d r}{\int_{0}^{\infty} e^{-\rho r}|\sin (\omega r)| d r}
$$


Во всех, практически значимых случаях, на интервале $\left[0, \mathrm{r}_{\mathrm{m}}\right]$ тригонометрическая функция успевает сделать большое число осцилляций:

$\omega r_{m} \gg \pi$, что позволяет воспользоваться теоремой о среднем:

$$
\Sigma_{\text {oтн }}(\omega)=C_{r_{m}}(\omega) \frac{\int_{0}^{r_{m}} e^{-\rho r} d r}{\int_{0}^{\infty} e^{-\rho r} d r} .
$$

Интегрируя (8), спектральную относительную отражательную способность получим в виде:

$$
\Sigma_{\text {отн }}(\omega)=C_{r_{m}}(\omega)\left(1-e^{-\rho r_{m}}\right)
$$

Поскольку частота $\omega$ выбрана произвольно, сделанные выводы с учетом использованных приближений можно распространить на любую частоту спектра, использованного в преобразовании (6). Регулярное поведение относительных отражательных способностей на фиксированной частоте позволяет распространить этот вывод и на относительную отражательную способность в целом:

$$
\Sigma_{\text {отн }}=\int_{0}^{\infty} \Sigma_{\text {отн }}(\omega) d \omega \approx C_{r_{m}}\left(1-e^{-\rho r_{m}}\right)
$$

где $\rho$ - проводимость, $\mathrm{r}_{\mathrm{m}}$ - толщины слоя.

В данном исследовании коэффициент $k$ оказался равным 25 для песка и 230 для глины.

Выше установлена связь пенетрации различных грунтов и георадиолокации. Однако для возможности использования показаний георадара для определения проходимости транспортных средств необходимо установления зависимости условной жесткости грунта с его отражающей способностью.

Такую связь можно получить, используя данные, полученные в рамках настоящей работы и известные зависимости теории движения колесных машин [3].

Для того чтобы определить численные значения параметров, характеризующих движение машины, как и принципиальную возможность ее движения, необходимо найти соотношения между силами и моментами ведущих колес и силами сопротивления движению, а также видами сцепления ведущих колес с опорной поверхностью [4-5].

При движении по неусовершенствованным дорогам и местности в качестве основной составляющей силы сопротивления движению будем рассматривать силу сопротивления качению колеса по деформируемой дороге или грунтовой поверхности, объединяя последнее одним понятием - дорожно-грунтовая поверхность.
Если в условиях бездорожья колесной машине приходится двигаться по неровностям местности, например по кочкам, их можно считать жесткими, либо в некоторых случаях заменять нормальную жесткость шин приведенной жесткостью системы шина-грунт

Силы взаимодействия колеса с дорожногрунтовой поверхностью во многом определяются свойством, или характеристикой, поверхности.

К дорожно-грунтовым поверхностям относятся различные проселочные, полевые и лесные дороги, характеризующиеся тем, что на них устранены в той или иной мере препятствии для движения и в большинстве случаев налажен элементарный отвод воды, но поверхность грунта специально не подготовлена. Движутся колесные машины и по профилированным грунтовым дорогам, и по естественным грунтовым поверхностям, совершенно не приспособленным для движения, по целине, по снежным дорогам и снежным поверхностям [6].

Основной особенностью грунтов является то, что они представляют собой дисперсное вещество, в котором среди массы мелко раздробленных тел могут находиться влага, воздух, остатки растительных и животных организмов. Следовательно, на механические свойства грунтов, которые в конечном итоге определяют взаимодействие колеса с грунтом, влияют размеры частиц этих твердых тел, плотность их размещения, степень заполнения пространства между частицами воздухом, влагой или продуктами органического происхождения. От этих характеристик зависит прочность связи между твердыми частицами, которая существенно меньше прочности самих частиц.

Одной из важнейших характеристик грунтов является гранулометрический состав, которым оценивается содержание в грунте частиц («гранул») различного размера.

По размеру твердые частицы обычно подразделяют на глинистые (до 0,005 мм), характеризуемые также липкостью, пылеватоилистые $(0,005 \ldots 0,05$ мм), песчаные $(0,05 \ldots 2,0$ MM).

Ниже приведена классификация грунтов по содержанию самых мелких, глинистых частиц:

Глинистый................Более $30 \%$
Суглинистый...................12\%
Супесчаный..................12...3\%
Песчаный.................... Менее $3 \%$

Глинистые и суглинистые грунты относятся также к связным грунтам, а песчаные - к сыпучим.

Важной характеристикой грунтов, особенно связных, является их влажность. Абсолютная 
влажность W определяется отношением массы влаги, содержащейся во взятом объеме грунта, к массе сухого вещества и выражается либо в относительных числах, либо в процентах.

Влажность грунта оказывает очень большое влияние на механические свойства грунтов, особенно связных. Связные грунты характеризуются наличием в них сил сцепления, зависящих от содержания влаги, вследствие чего эти грунты могут быть твердыми, пластичными или текучими. Вода, находящаяся в грунтах, влияет на их свойства по-разному. При незначительном увлажнении вода увеличивает связность грунта. Но с повышением содержания воды, когда она заполняет в грунте более крупные поры, связность грунта снижается. При достижении влажности, соответствующей пределу текучести, но разной для различных грунтов, грунты переходят из пластичного состояния в текучее. В этом состоянии связность грунта и его сопротивление нагрузкам ничтожны. При влажности, соответствующей пределу пластичности, грунт переходит из пластичного состояния в твердое. Разность между пределами текучести и пластичности называют числом пластичности.

Сыпучие грунты характеризуются отсутствием сцепления между частицами грунта в сухом состоянии.

В классификации грунтов можно выделить еще заболоченные грунты (или торф), состоящие в основном из разложившихся остатков животных или растений.

Одной из характеристик грунтов является пористость - отношение объема пор к объему грунта или коэффициент пористости е, представляющий отношение объема $V_{n}$ пор грунта к объему $V_{i}$ скелета грунта.

При выпадении осадков больше увлажняются разрыхленные грунты, например пашня, в которых относительный объем пор наибольший, меньше - задернованные (стерня, луг) и еще меньше - уплотненные грунты (например, грунтовые дороги), в которых объем пор наименьший. Снег имеет различную структуру и размеры частиц, его свойства изменяются в зависимости от внешних условий больше, чем многих грунтов.

Bce грунты, a также снег, можно характеризовать, как любые вещества, плотностью, т. е. отношением массы грунта к его объему.
Практически все грунты лежат на твердом основании, причем толщина мягкого слоя грунта колеблется в диапазоне от единиц до нескольких десятков сантиметров, а в остальных случаях, например на заболоченных участках, - до нескольких метров.

Из механических характеристик грунтов важнейшими для оценки движения колесных машин являются две, которые определяют взаимодействие колеса с грунтовым основанием: нормальная деформируемость грунтов под действием основной по величине силы тяжести машины и касательная деформируемость под действием тангенциальных сил колес. Во многих случаях одновременно происходят обе деформации грунтов. Так, под действием вертикальной нагрузки нормальная деформация может сопровождаться выдавливанием грунта в стороны, которое незначительно на сыпучих грунтах, но на связных грунтах в пластичном и текучем состоянии касательная деформация является основной или, по крайней мере, такой же, как нормальная [7-8]. Тангенциальная сила вызывает не только уплотнение или сдвиг грунта параллельно опорной поверхности в направлении движения, но и деформацию грунта в нормальном направлении.

Характеристики грунтов изучаются широким кругом специалистов: строителями зданий, дорожниками и др. Для большей общности грунты при исследовании этих характеристик нагружают специальными штампами - площадками, посредством которых производятся давление на грунт и его деформация. Штампы могут иметь различную форму (в частности, неплоскую) и размеры. Однако в любом случае они должны быть жесткими. Установив основные закономерности деформируемости грунта при нагружении его штампом, можно затем с соответствующей коррекцией перенести их на случай деформации грунта под катящимся колесом. Рассмотрим характер зависимости деформации грунта под действием нормальной нагрузки, причем, поскольку грунт - дисперсное вещество, будем учитывать действие на грунт не сосредоточенных сил, а давлений.

На рисунках $8 \quad-10$ представлены зависимости изменения удельной несущей способности различных типов грунтов от влажности. 


\begin{tabular}{l|lrl|l|ll} 
& ISRA (India) & $=\mathbf{1 . 3 4 4}$ & SIS (USA) & $=\mathbf{0 . 9 1 2}$ & ICV (Poland) & $=\mathbf{6 . 6 3 0}$ \\
Impact Factor: & ISI (Dubai, UAE) $=\mathbf{0 . 8 2 9}$ & PUHU (Russia) $=\mathbf{0 . 1 7 9}$ & PIF (India) & $=\mathbf{1 . 9 4 0}$ \\
& GIF (Australia) & $\mathbf{0 . 5 6 4}$ & ESJI (KZ) & $=\mathbf{1 . 0 4 2}$ & IBI (India) & $\mathbf{4 . 2 6 0}$
\end{tabular}

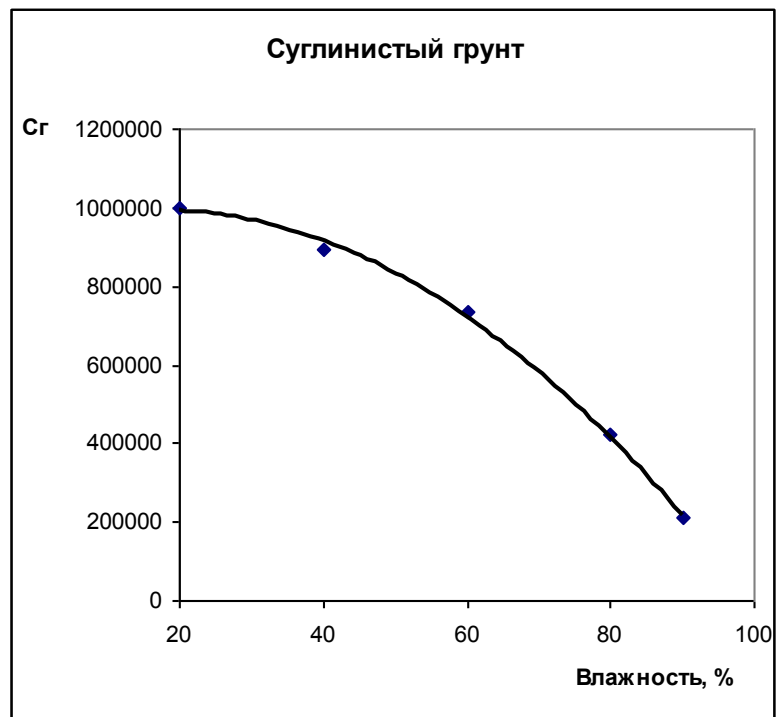

Рисунок 8 - Изменение удельной несущей способности суглинистого грунта от влажности.

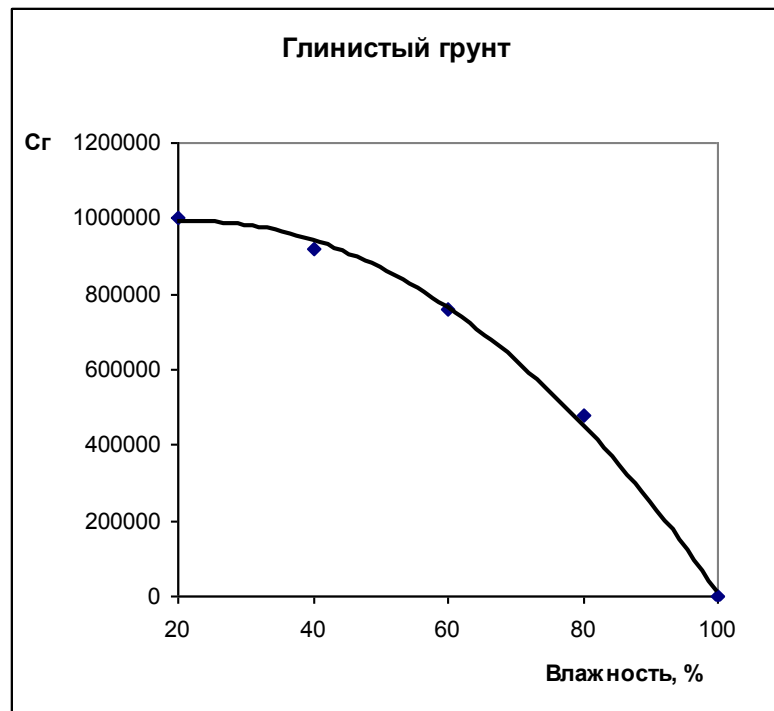

Рисунок 9 - Изменение удельной несущей способности глинистого грунта от влажности.

В свою очередь, экспериментально установлена связь отражающей способности грунта от его влажности.

Использование численных значений позволяет получить регрессионными методами функциональную зависимость, связывающую удельную несущую способность грунтов $c_{2}$ с их отражающей способностью $\Sigma$. 


\begin{tabular}{l|lrl|l|ll} 
& ISRA (India) & $=\mathbf{1 . 3 4 4}$ & SIS (USA) & $=\mathbf{0 . 9 1 2}$ & ICV (Poland) & $=\mathbf{6 . 6 3 0}$ \\
Impact Factor: & ISI (Dubai, UAE) $=\mathbf{0 . 8 2 9}$ & PUHU (Russia) $=\mathbf{0 . 1 7 9}$ & PIF (India) & $=\mathbf{1 . 9 4 0}$ \\
& GIF (Australia) & $\mathbf{0 . 5 6 4}$ & ESJI (KZ) & $=\mathbf{1 . 0 4 2}$ & IBI (India) & $\mathbf{4 . 2 6 0}$
\end{tabular}

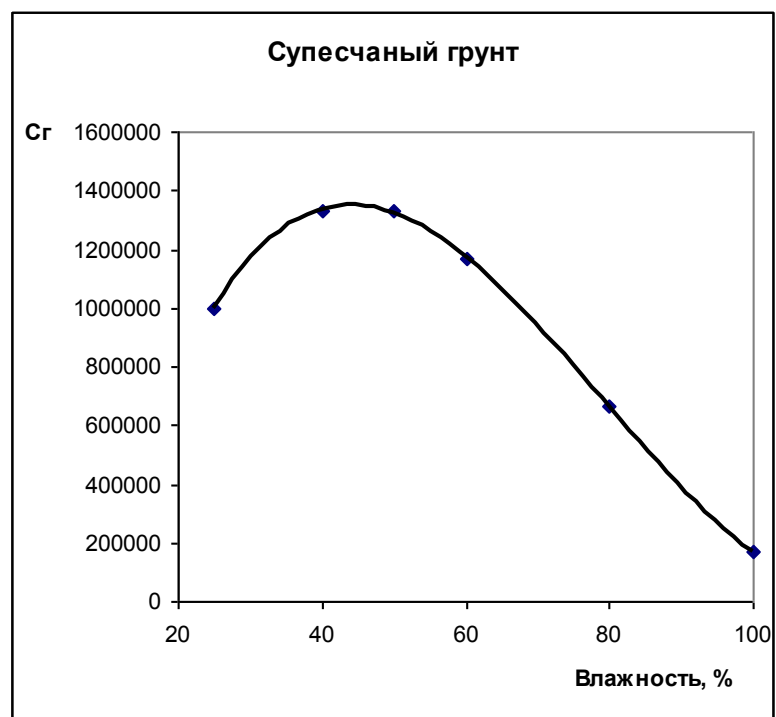

Рисунок 10 - Изменение удельной несущей способности супесчаного грунта от влажности.

Такого рода зависимость представлена выражением 12:

$c_{\Gamma}=\alpha \cdot \exp (\beta \cdot \Sigma)+\gamma \cdot \exp (\delta \cdot \Sigma)+\theta$,

Здесь $\alpha, \beta, \gamma, \theta$ эмпирические коэффициенты для различных типов грунтов. Численные значения этих коэффициентов для глинистого и суглинистого грунта представлены в таблице 4. На рисунке 11 представлена графическая интерпретация выражения 12.

Значения коэффициентов $\alpha, \beta, \gamma, \boldsymbol{\theta}$.

Таблица 4

\begin{tabular}{|c|c|c|c|c|}
\hline Тип грунта & $\alpha$ & $\beta$ & $\gamma$ & $\theta$ \\
\hline Глина & $3.0110^{-2}$ & $-2.6210^{-9}$ & 16.6 & $910^{5}$ \\
\hline Суглинок & $1.9210^{-2}$ & $-2.3110^{-9}$ & 16.6 & $9.510^{5}$ \\
\hline
\end{tabular}

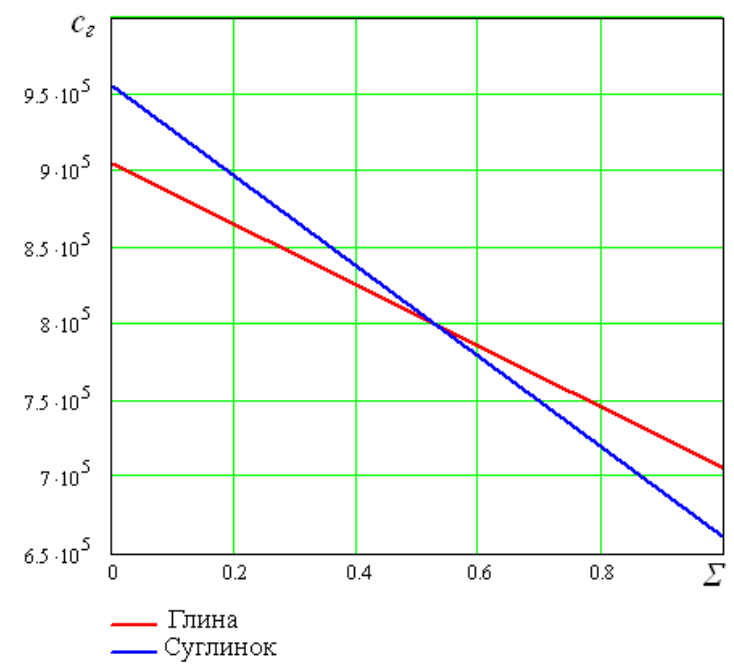

Рисунок 11 - Графическая интерпретация выражения 12. 


\begin{tabular}{l|lrl|l|ll} 
& ISRA (India) & $=\mathbf{1 . 3 4 4}$ & SIS (USA) & $=\mathbf{0 . 9 1 2}$ & ICV (Poland) & $=\mathbf{6 . 6 3 0}$ \\
Impact Factor: & ISI (Dubai, UAE) $=\mathbf{0 . 8 2 9}$ & PUHL (Russia) $=\mathbf{0 . 1 7 9}$ & PIF (India) & $=\mathbf{1 . 9 4 0}$ \\
& GIF (Australia) & $\mathbf{0 . 5 6 4}$ & ESJI (KZ) & $=\mathbf{1 . 0 4 2}$ & IBI (India) & $=\mathbf{4 . 2 6 0}$ \\
& JIF & $\mathbf{1 . 5 0 0}$ & SJIF (Morocco) & $=\mathbf{2 . 0 3 1}$ & & \\
\hline
\end{tabular}

В заключении следует отметить, что вне зависимости от типа грунта до $80 \%$ наблюдается хорошая корреляция между данными динамической пенетрации и георадиолокации. Однако для применения полученных результатов необходимо иметь априорную информацию о природе грунта, которая необходима для корректного выбора коэффициента $k$.
Зависимость, связывающая удельную несущую способность грунтов $c_{2}$ с их отражающей способностью $\Sigma$ может быть использована для оценки проходимости транспортного средства по результатам георадиолокационного мониторинга грунтового полотна дороги [9-10].

\section{References:}

1. (2001) GOST 19912-2001.

2. Konshin GG (2007) Diagnostika zemlyanogo polotna zheleznyh dorog. Moscow: GOU «Uchebno-metodicheskij centr po obrazovaniyu na zheleznodorozhnom transporte», 2007. - 200 p.

3. Smirnov GA (1990) Teoriya dvizheniya kolesnyh mashin. Moscow: Mashinostroenie, 1990, $352 \mathrm{p}$.

4. (2015) Prognozirovanie mesta razrusheniya konstrukcij. Reshenkin A.S. Stredoevropsky Vestnik pro Vedu a Vyzkum. 2015. T. 84. pp. 33.

5. (2015) Siloizmeritel'naya sistema. Goncharov A.V., Kostoglotov A.A., Reshenkin A.S. Stredoevropsky Vestnik pro Vedu a Vyzkum. 2015. T. 75. pp. 53.

6. (2014) Vvedenie v professional'nuju dejatel'nost'. Vorob'ev S.S., Vorob'ev S.A. (servis transportnyh sredstv) uchebnoe posobie / Pechataetsja po resheniju redakcionnoizdatel'skogo soveta Donskogo gosudarstvennogo tehnicheskogo universiteta. Rostov-na-Donu, 2014.

7. (2015) Diagnostika ciklicheski deformiruemyh konstrukcij. Reshenkin A.S., Kayukov A.A. Stredoevropsky Vestnik pro Vedu a Vyzkum. 2015. T. 84. pp. 36.

8. (2007) Ehffektivnost' primeneniya sredstv nearzrushayushche go kontrolya i diagnostiki. Reshenkin A.S. Gruzovik. 2007. № 2. pp. 1114.

9. (2010) GEORADIOLOKACIONNYJ SPOSOB OPREDELENIYA NESUSHCHEJ SPOSOBNOSTI GRUNTOV Zaharov V.A., Korobchanu S.G., Pogorelov N.P., Reshenkin A.S., Tihomirov A.G., CHernichenko R.A. patent na izobretenie RUS 2416116 08.02.2010

10. (2010) USTROJSTVO GEORADIOLOKACIONNOJ OCENKI NESUSHCHEJ SPOSOBNOSTI GRUNTOVZaharov V.A., Korobchanu S.G., Pogorelov N.P., Reshenkin A.S., Tihomirov A.G., CHernichenko R.A. patent na izobretenie RUS 2419110 09.03.2010 